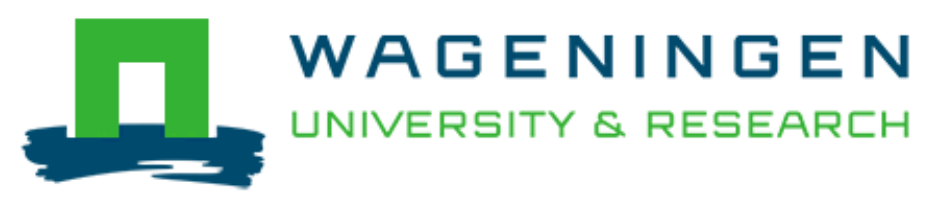

Allometric equations for yield predictions of enset (Ensete ventricosum) and khat (Catha edulis) grown in home gardens of southern Ethiopia

Mellisse, B. T., Descheemaeker, K., Mourik, M. J., \& van de Ven, G. W. J.

This article is made publically available in the institutional repository of Wageningen University and Research, under article $25 \mathrm{fa}$ of the Dutch Copyright Act, also known as the Amendment Taverne.

Article $25 \mathrm{fa}$ states that the author of a short scientific work funded either wholly or partially by Dutch public funds is entitled to make that work publicly available for no consideration following a reasonable period of time after the work was first published, provided that clear reference is made to the source of the first publication of the work.

For questions regarding the public availability of this article, please contact openscience.library@wur.nl.

Please cite this publication as follows:

Mellisse, B. T., Descheemaeker, K., Mourik, M. J., \& van de Ven, G. W. J. (2017). Allometric equations for yield predictions of enset (Ensete ventricosum) and khat (Catha edulis) grown in home gardens of southern Ethiopia. Annals of Applied Biology, 171(1), 95-102. https://doi.org/10.1111/aab.12350 


\title{
Allometric equations for yield predictions of enset (Ensete ventricosum) and khat (Catha edulis) grown in home gardens of southern Ethiopia
}

\author{
B.T. Mellisse ${ }^{1,2}$, K. Descheemaeker ${ }^{1}$, M.J. Mourik ${ }^{1}$ \& G.W.J. van de Ven ${ }^{1}$ \\ 1 Plant Production Systems, Wageningen University and Research (WUR), Wageningen, The Netherlands \\ 2 Wondo Genet College of Forestry and Natural Resources, Hawassa University, Shashemene, Ethiopia
}

Keywords
Home gardens; model performance; plant
structure; plant yield.

Correspondence

B.T. Mellisse, Plant Production Systems,

Wageningen University and Research (WUR), PO

Box 430, Wageningen $6700 \mathrm{HB}$, The

Netherlands. Email: beyene.mellisse@wur.n

Received: 16 August 2016; revised version accepted: 29 December 2016; published online: 18 April 2017.

doi:10.1111/aab.12350

\begin{abstract}
Enset is a large, single-stemmed perennial herbaceous plant domesticated as a staple food crop only in Ethiopia. Khat is a perennial plant cultivated for its economically important leaves and twigs that are the sources of stimulant when chewed. We address the issue of yield estimation of both crops, as they are important for the livelihoods of smallholders in the home garden systems in Southern Ethiopia and have received little attention so far. The objective of this study was to develop linear allometric models for estimating the edible (food and feed) and commercial yields of enset and khat plants, respectively. Data were collected from 20 enset and 100 khat plants. Diameter at 50-cm height $\left(d_{50}\right)$, pseudostem height $\left(h_{p}\right)$ and their combination were good predictor variables for the food products of enset with adjusted $R^{2}$ values above 0.85 , while $d_{50}, h_{p}$, edible pseudostem height $\left(h_{e p}\right)$, total height $\left(h_{t}\right)$ and their combination were good predictor variables for the feed products of enset with adjusted $R^{2}$ values above 0.70 . For dwarf khat plants crown area ( $c a$ ) combined with total height $\left(h_{t}\right)$ resulted in the best prediction with an adjusted $R^{2}$ of 0.77 , while the leaf and twig dry weight for tall khat plants was best predicted by ca with adjusted $R^{2}$ of 0.43 . In all cases linear models were used.
\end{abstract}

\section{Introduction}

Enset (Enset ventricosum (Welw.) Cheesman) is produced in the home gardens of southern and southwestern Ethiopia and provides food for more than 15 million people (Abebe et al., 2010). Enset is a large, single-stemmed perennial herbaceous banana-like plant, domesticated as a staple food crop only in Ethiopia (Brandt et al., 1997; Negash \& Niehof, 2004). Besides being a food source, enset leaves are a key livestock feed and used as mulch to reduce soil erosion and runoff (Amede $\delta$ Taboge, 2005).

Khat (Catha edulis Forsk) is a flowering woody perennial plant, grown for its economically important leaves and tender twigs, which are chewed for their stimulating effect (Megerssa et al., 2013). Ethiopia is widely believed to be the world's largest producer of khat (Seyoum, 2015). More than two million farmers are engaged in khat farming, most of whom are smallholders. The scarcity of farmland combined with the profitability of khat (Teklu et al., personal communication) explains the surge in khat cultivation among smallholder farmers across the country (Dessie, 2013).

Enset and khat are important crops for the livelihoods of the smallholders in the home garden systems and have received little attention so far. Monitoring impacts of innovations and their implications on the livelihoods of smallholder farmers require rapid and reliable means of quantifying the yields of these crops.

Existing studies on enset have focused on its management and ecological roles (Brandt et al., 1997), genetic pool and landraces (Tesfaye, 2008a, 2008b) and its carbon sequestration potential (Negash et al., 2013). The studies on khat dealt with the impact of the plant on public health (Geresu, 2015), livelihood, policy and trade conditions (Dessie, 2013; Njiru et al., 2013; Kandari et al., 2014). The laborious and complicated harvesting and processing procedures of enset 
(Tsegaye \& Struik, 2001) and the piece-meal harvesting of khat (Feyisa $\&$ Aune, 2003) have been reported as major challenges for reliable yield assessments. Nevertheless, little attention has been given to develop easy ways of estimating the yields of both perennial crops. A recent study reported allometric models for the above and belowground biomass of enset (Negash et al., 2013), but neglected its processed edible products called kocho and bula. Allometric equations using simple measurable plant variables as predictors for edible or commercial plant yield are time-saving tools providing valuable information for identifying productivity challenges and solutions for improving smallholders' food production and cash income.

The overall objective of this study was therefore to develop and evaluate allometric models for estimating the edible and commercial yields of enset and khat grown in home gardens of southern Ethiopia.

\section{Materials and methods}

The study was conducted in the Sidama zone $\left(5^{\circ} 45^{\prime}-6^{\circ} 45^{\prime} \mathrm{N}\right.$ and $\left.38^{\circ} 5^{\prime}-39^{\circ} 41^{\prime} \mathrm{E}\right)$ of Southern Nations Nationalities and Peoples' Regional State (SNNPRS), southern Ethiopia. Traditional Enset-oriented and newly evolving Khat-based home gardens are the prevalent farming systems (Teklu et al., personal communication).

\section{Measurement of plant structural variables and biomass}

\section{Enset}

A total of 20 enset plants from four farms (five enset plants from two farms in each of the mid-altitude and highland agro-ecology) were selected randomly for measurement and harvesting. The two agro-ecologies are characterised by predominant clay-loam to silt-loam soils in the mid-altitude zone (1500-2300 m a.s.l.) and sandy-loam to sandy-clay soils in the highland zone (2300-3200 m a.s.l.). The 20 enset plants covered the different landraces and age range of harvestable enset in the study area of 3-7 years after transplanting. Before felling the diameter of the pseudostem was measured with a calliper at a height of $20 \mathrm{~cm}$ (the height where the stem is widest, $\left.d_{20}\right)$, at $50 \mathrm{~cm}$ (diameter, $\left.d_{50}\right)$, at $130 \mathrm{~cm}$ (breast height, $\left.d_{130}\right)$ and at edible pseudostem height $\left(d_{e p}\right)$ (Table 1). Edible pseudostem height $\left(h_{e p}\right)$, pseudostem height $\left(h_{p}\right)$ and total height $\left(h_{t}\right)$ were measured with a tape measure and crown height $\left(h_{c}\right)$ was calculated by subtracting $h_{p}$ from $h_{t}$. The total height refers to the distance from the ground to the distal lamina of the last leaf to emerge. After measuring, the sample plants were dug up and separated into three components: corm, pseudostem and foliage. The corm is the edible underground portion of enset plants. The pseudostem is formed of leaf sheaths, lying one over the other in a concentric fashion; the foliage (leaf) component is comprised of the petiole, leaf midribs and leaf lamina. The fresh weight of each component was determined on-site and samples were taken to the laboratory, chopped, sun dried for 5-6 days and then oven dried at $65^{\circ} \mathrm{C}$ for $24 \mathrm{~h}$. To obtain kocho from the pseudostem, the common processing procedure by farmers was followed. The pseudostem was cut into several pieces and the pulp (parenchymatous tissue) was scraped using a sharp-edged bamboo tool. The corm was pulverised using a wooden tool with a flat sharp edge. The scraped pseudostem mixed with pulverised corm of each plant was stored in a pit for 18-21 days for fermentation. A small separate pit was dug to collect the fine starchy liquid draining from the mixture in the large pit. The fine starchy liquid was sun dried and the resulting flour is called bula. Bula was collected from 14 enset plants, as it can only be extracted from older plants ( $>4$ years of age). After 3 weeks of fermentation, the fresh kocho and bula were collected and weighed on-site. To determine the dry weight content, a sample of kocho and bula was taken to the lab, sun dried for 5-6 days and then oven dried at $65^{\circ} \mathrm{C}$ for $24 \mathrm{~h}$.

\section{Khat}

Marketable leaves and twigs of khat were collected for two different khat growth habit types: tall khat is grown for 3-4 years up to a height of $4 \mathrm{~m}$ without pruning and dwarf khat is pruned at an earlier stage and maintained at a maximum height of $1 \mathrm{~m}$. For each type, samples were taken from 50 plants (five khat plant from 5 farms of each mid-altitude and highland agro-ecology) on the harvesting day. The 100 khat plants captured the genetic variability in the region by covering the three different ecotypes known as 'wondo beleche', 'wugigra' and 'chenge', which are all three managed as dwarf or tall plants. The diameter at a height of $10 \mathrm{~cm}$ (basal diameter, $d_{10}$ ), at $130 \mathrm{~cm}$ (breast height, $d_{130}$ ), crown width in two directions (the widest diameter and its perpendicular), crown height $\left(h_{c}\right)$ and total height $\left(h_{t}\right)$ were measured (Table 1). Marketable leaves and twigs were harvested from each plant and weighed on-site. All leaves and twigs were taken to the laboratory, sun dried for 2-3 days and then oven dried at $65^{\circ} \mathrm{C}$ for $24 \mathrm{~h}$. In case of multi-stemmed plants, each stem was measured and the equivalent diameter of the plant was calculated using the formula developed by Snowdon et al. (2002) as:

$$
d e=\sqrt{\sum_{i}^{n} d \mathrm{i}^{2}}
$$


Table 1 Summary statistics of crop structure variables of harvested enset and khat plants

\begin{tabular}{|c|c|c|c|c|}
\hline Parameters & Mean & Minimum & Maximum & SD \\
\hline \multicolumn{5}{|l|}{ Enset $(n=20)$} \\
\hline$d_{20}(\mathrm{~cm})$ & 47.1 & 26 & 60 & 10.6 \\
\hline$d_{50}(\mathrm{~cm})$ & 39.2 & 16 & 57 & 13.4 \\
\hline$d_{130}(\mathrm{~cm})$ & 26.4 & 14 & 40 & 8.0 \\
\hline$d_{e p}(\mathrm{~cm})$ & 22.4 & 14 & 30 & 5.0 \\
\hline Edible pseudostem height (m) & 1.670 & 0.60 & 3.28 & 0.669 \\
\hline Pseudostem height (m) & 2.174 & 0.80 & 3.60 & 0.778 \\
\hline Crown height (m) & 3.161 & 1.05 & 6.20 & 1.502 \\
\hline Total height (m) & 5.335 & 2.82 & 8.79 & 1.703 \\
\hline \multicolumn{5}{|l|}{ Dwarf khat type $(n=50)$} \\
\hline$d_{10}(\mathrm{~mm})$ & 17.31 & 9.7 & 29.7 & 4.68 \\
\hline Crown area $\left(\mathrm{m}^{2}\right)$ & 0.195 & 0.07 & 0.35 & 0.071 \\
\hline Total height (m) & 0.745 & 0.45 & 1.03 & 0.161 \\
\hline \multicolumn{5}{|l|}{ Tall khat type $(n=50)$} \\
\hline$d_{10}(\mathrm{~mm})$ & 61.88 & 27.1 & 185.8 & 24.18 \\
\hline$d_{130}(\mathrm{~mm})$ & 44.08 & 10.5 & 154.3 & 25.41 \\
\hline Crown area $\left(\mathrm{m}^{2}\right)$ & 0.757 & 0.26 & 1.33 & 0.264 \\
\hline Crown height (m) & 1.207 & 0.47 & 2.73 & 0.443 \\
\hline Total height (m) & 2.453 & 1.31 & 3.64 & 0.555 \\
\hline
\end{tabular}

$\mathrm{SD}=$ standard deviation of the original data

where $d e=$ equivalent diameter, $n=$ number of stems, $i=1,2, \ldots, n$ and $d_{i}=$ single stem diameter of the same plant at a selected height.

Crown area was calculated as follows, assuming an elliptic crown shape:

$$
c a=\pi\left(\frac{l w}{4}\right)
$$

where $c a=$ crown area $\left(\mathrm{m}^{2}\right), l=$ crown length $(\mathrm{m})$, $w=$ crown width $(\mathrm{m})$

\section{Allometric model development}

Allometric linear regression models using untransformed and log-transformed data were determined for each of the food products (kocho and bula) and feed product (foliage) of enset and the leaves and twigs of khat. When the original data did not show a linear pattern, log transformations of the data were performed. Single log transformations based on the response variable (biomass component) only and double log transformations based on both the biomass and crop structure variables were performed. Model performance was tested using the adjusted coefficient of determination (adj. $R^{2}$ ), root mean square error (RMSE), prediction residuals sum of squares (PRESS), index of agreement $(D)$ and absolute bias (AB) (Kozak \& Kozak, 2003). These model fit statistics were calculated based on all observations that were used in constructing the models.

$$
\operatorname{adj} \cdot R^{2}=1-\left(1-R^{2}\right) \frac{(n-1)}{n-p-1}
$$

$$
\begin{gathered}
R^{2}=1-\frac{\sum_{n=1}^{n}\left(Y_{i}-\widehat{Y}_{i}\right)^{2}}{\sum_{n=1}^{n}\left(Y_{i}-\bar{Y}\right)^{2}} \\
\operatorname{RMSE}=\sqrt{\frac{\sum_{n=1}^{n}\left(Y_{i}-\hat{Y}_{i}\right)^{2}}{n}} \\
\operatorname{PRESS}=\sum_{n=1}^{n}\left(Y_{i}-\hat{Y}_{i},-i\right)^{2} \\
\sum_{n=1}^{n}\left(\left|\hat{Y}_{i}-\bar{Y}_{i}\right|+\left|Y_{i}-\bar{Y}_{i}\right|\right)^{2} \\
\operatorname{AB}=\frac{\left.\sum_{n=1}^{n} \mid \hat{Y}_{i}-Y_{i}\right)^{2}}{n}
\end{gathered}
$$

where $n$ =number of observations, $i=1,2, \ldots, n$; $p=$ number of predictors, $Y_{i}$ is the observation of the response variable, $\hat{Y}_{i}$ is the predicted value of $Y_{i}, \bar{Y}$ is the average of $Y_{i}, \hat{Y}_{i,-i}$ is the prediction of the $i^{\text {th }}$ data point by an equation that did not make use of the $i^{\text {th }}$ point in the estimation of the parameters. A good model has high adj. $R^{2}$ and $D$ and low RMSE, PRESS and AB values. 


\section{Model selection}

To select the best performing models, first-cut model selection criteria were applied. The approach was to select linear models consisting of one or more crop structural variables as predictors of the crop biomass. This selection was obtained with the leaps package in RStudio (RStudio, 2015) based on two algorithms; the first based on the highest adjusted $R^{2}$ and the second based on the lowest BIC (Bayesian Information Criterion). Dependent on the adjusted $R^{2}$, the 10 best performing models were listed for more detailed analysis. This was done for both the single and double log transformation, yielding around 20 models per response variable. Only models with coefficients significantly different from zero were retained. This prerequisite was not applied to the intercept. The models were ranked according to each goodness-of-fit statistic and then the ranks were summed. The lowest total ranking value was deemed to indicate the best model. The best predictor of the crop structure variables was plotted against the plant biomass and the equal spread of points in residual plots was evaluated. For simplicity in use and interpretation of the equation, a linear model is preferred over non-linear models for this study. These models could be used as a basis for developing enset and khat crops growth or yield simulation models.

\section{Results}

The five best performing models for kocho, bula, foliage of enset and leaves and twigs of dwarf and tall khat are shown in Table 2. The single log transformed model with $d_{50}$ performed best for dry weight of kocho. The model explained up to $89 \%$ of the variation in kocho dry weight. The double log transformed model for kocho dry weight using pseudostem height $\left(h_{p}\right)$ and crown height $\left(h_{c}\right)$ combined with diameter variables $\left(d_{20}\right.$ and $\left.d_{50}\right)$ had a slightly smaller adjusted $R^{2}$ of 0.87 (Table 2). The combination of $d_{50}$ with two height variables in a double log transformed model explained $85 \%$ of the variation in bula dry weight. The same combination in a single log transformed model performed only slightly worse. The other models which combine $d_{50}$ with $h_{c}$ and $d_{50}$ with $h_{t}$, respectively explained $78 \%$ and $79 \%$ of the variation in bula dry weight (Table 2). The double log transformed model including $d_{50}$ combined with height variables explained $72 \%$ of variation in foliage dry biomass. The linear model performances for edible products of enset plants were better than the foliage (Table 2). The best performing kocho and bula dry biomass models had index agreement $(D)$ values greater than 0.94 and values of less than $0.5,4$ and 0.4 for RMSE, PRESS and AB, respectively, indicating a good agreement between modelled and measured biomass values of all models.
Of the four diameter variables $\left(d_{20}, d_{50}, d_{130}\right.$ and $\left.d_{e p}\right)$ diameter at $50 \mathrm{~cm}$ height $\left(d_{50}\right)$ was the best predictor variable for kocho, bula and foliage. Diameter at breast height $\left(d_{130}\right)$ and diameter at edible pseudostem height $\left(d_{e p}\right)$ were not included in any of the models for kocho, bula and foliage. Of the four height variables $\left(h_{e p}, h_{p}, h_{t}\right.$ and $h_{c}$ ) pseudostem height $\left(h_{p}\right)$ and total height $\left(h_{t}\right)$ were not included in the five best performing models for kocho, whereas all height variables were included in those for bula and foliage (Table 2).

The single log transformed models combining crown area $(c a)$ and total height $\left(h_{t}\right)$ performed best for dwarf khat leaves and twig weight while models using only ca performed best for tall khat (Table 2). The models explained $77 \%$ and $43 \%$ of the variation in leaf and twig dry weight for dwarf and tall khat, respectively. Both diameter at basal height $\left(d_{10}\right)$ and diameter at breast height $\left(d_{130}\right)$ were not included in any of the models. The adjusted $R^{2}$ and index of agreement $(D)$ values of untransformed models for tall khat improved when crown height $\left(h_{c}\right)$ or total height $\left(h_{t}\right)$ was included, however, the degree of agreement in terms of RMSE, PRESS and $\mathrm{AB}$ between modelled and measured biomass values decreased (Table 2).

Similar to kocho and bula, log transformed models performed well for predicting leaf and twig dry weight of khat. The overall degree of agreement between modelled and measured biomass values of the five best performing models decreased in the order: kocho $>$ bula $>$ dwarf khat $>$ enset foliage $>$ tall khat dry weight prediction. The adjusted $R^{2}$ and index of agreement $(D)$ values for the models estimating the dry weight of the edible enset parts was higher than those for the enset foliage and khat dry weight (Table 2). Linear models had substantially higher adjusted $R^{2}$ for enset and dwarf khat and their residual plot showed a better equal spread around zero compared to tall khat (Table 2, Fig. 1).

\section{Discussion}

The best performing models explained $84 \%-89 \%$ of the variation in kocho, $78 \%-85 \%$ in bula and $60 \%-72 \%$ in foliage dry biomass (Table 2). These values are higher than those reported by Negash et al. (2013) for the pseudostem and corm components of enset, from which kocho and bula are processed and for foliage biomass of enset. The model performance of the linear allometric equations derived in this study is comparable and sometimes better than the non-linear models developed for biomass components of enset reported by Negash et al. (2013). The good performance of the linear models in this study could be related to the sampling of all harvestable age ranges (3-7 years) of enset plants, unlike the focus on only 


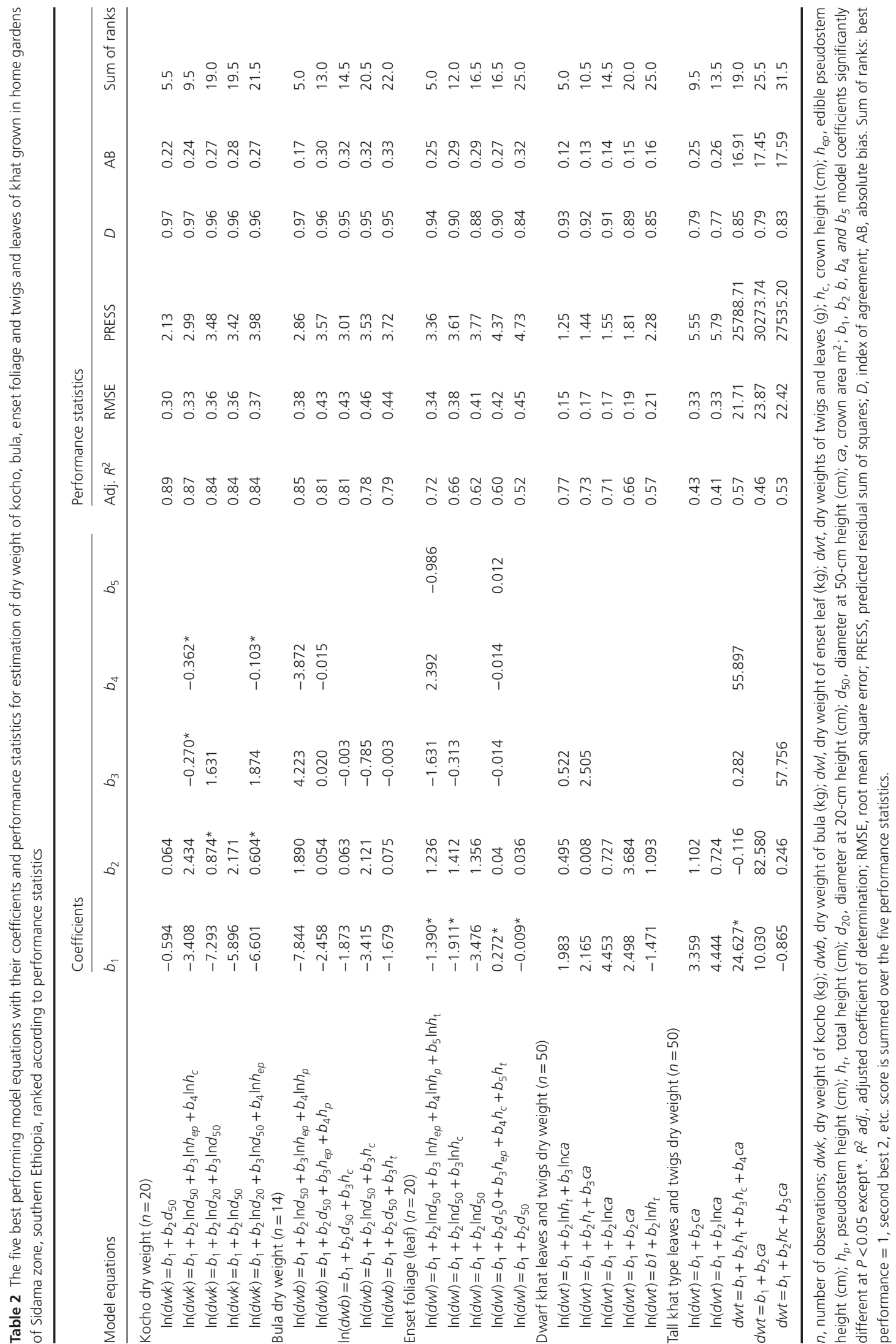



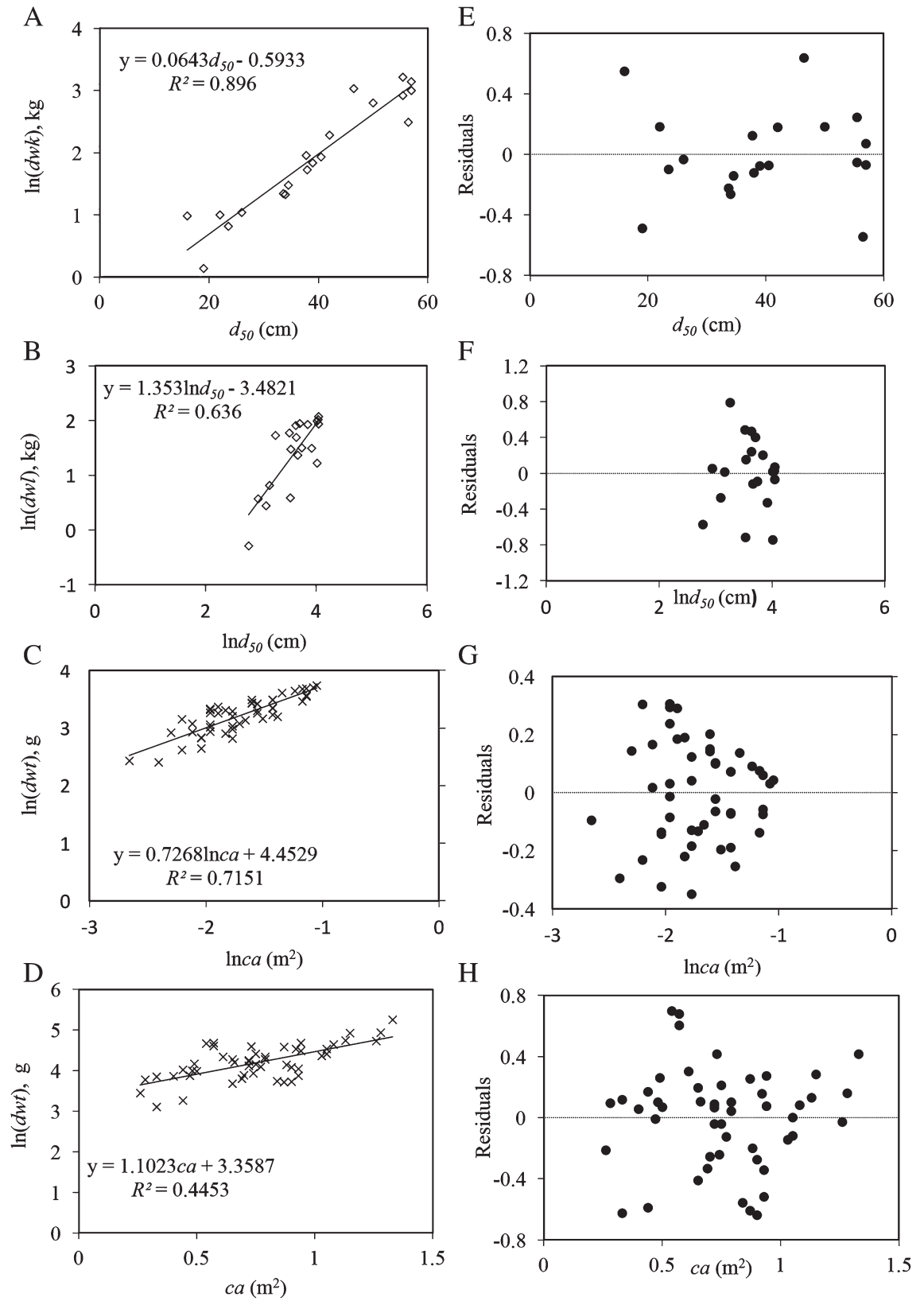

Figure 1 Relationships between basal diameter $\left(d_{50}\right)$ and kocho dry weight $(\ln (d w k))$ and enset leaf $(\operatorname{In}(d w /))(\mathrm{A}, \mathrm{B})$, crown area $(c a)$ with leaves and twigs dry weight $(\ln (d w t))$ for dwarf and tall khat type $(C, D)$ and their corresponding plots of residuals $(E, F, G$ and $H)$, respectively.

3- and 5-year enset plants by Negash et al. (2013). Diameter measurements were better predictor variables for kocho than height, indicating that kocho yield is more influenced by diameter growth than by the height growth. This is similar to the findings of another study, which reported a strong correlation between pseudostem biomass and diameter (Negash et al., 2013). Bula yield was best predicted by combined measurements of diameter and height variables, indicating that the yield is influenced by both diameter and height growth. This is in line with Tsegaye and Struik (2003) who reported a strong correlation of pseudostem circumference and height variables with pseudostem and corm, which are the enset components from which bula is extracted. This is also in line with the observations that bula is only harvested from older plants ( $>4$ years).

To our knowledge, there is no information on either quantitative determination of khat yield or an attempt to 
predict its biomass using allometric equations. The khat yield is mostly expressed in terms of financial returns (Feyisa \& Aune, 2003), which do not enable the quantification of field or farm level dry matter production. Crown area turned out to be the best predictor for leaf and twig dry weight of both dwarf and tall khat plants, which seems logical, because the harvestable leaves and twigs constitute the crown. Among the height variables, total height $\left(h_{t}\right)$ was the best predictor for dwarf khat plant while it was not for tall khat plants (Table 2). This implies that dwarf khat twig yield is influenced by expansion of crown area and height growth while the tall khat leaf and twig yield is mainly influenced by crown area expansion. This may be related to the management practices such as growing multiple stems by pruning at lower height for dwarf khat and growing of a single stem plant at larger height with larger crown area for tall khat (Table 1). The observed higher values of RMSE, PRESS and AB with the inclusion of height variables in the model developed for tall khat plants implies lower performances of model equations in predicting leaf and twig dry weight of khat plants.

Destructive sampling of enset is difficult due to its size and the lengthy harvesting and processing procedure. For khat, the difficulties lie in farmers' refusal to sample, which is related to costs and protectiveness. In such situations, allometric equations can help to rapidly quantify the yields of these crops, and quantify the productivity of home garden systems, which has rarely been done (Kumar \& Nair, 2004). This helps to explore sustainable development options in order to improve social and economic development of smallholder farmers. In addition, allometric equations can be a basis for the development of crop growth simulation models. This requires monitoring of biomass growth over time, for which allometric relations, based on simple measurements of plant structure can be used. Allometric equations for banana, a crop resembling enset, were successfully developed and applied to assess the water and nutrient limited banana production (Taulya, 2013) and to develop a banana growth simulation model in Uganda (Nyombi et al., 2009). We purposively sampled enset and khat plants from the existing range in agro-ecological conditions, land races and age classes. Hence, notwithstanding the small sample size, the allometric equations derived for these plants can be applied reliably to assess the yields of the diverse land races or ecotypes grown under a wide range of biophysical and management conditions.

\section{Conclusion}

The log transformed linear model including diameter $\left(d_{50}\right)$ performed best for predicting kocho dry weight while models including $d_{50}$ and height variables predicted bula and foliage dry biomass best. The log transformed linear model including total height $\left(h_{t}\right)$ and crown area $(c a)$ was the best performing model for predicting leaf and twig dry weight of khat. The performance of linear models was better for enset biomass prediction compared with khat. Simple linear equations based on easily measurable crop structure variables can provide reliable predictions of harvestable biomass for enset and khat plants grown in home gardens of southern Ethiopia. This paves the way for a thorough quantification of the productivity of home gardens.

\section{Acknowledgements}

This research was funded by the government of the Netherlands through the project Capacity building for scaling up of evidence-based best practices in agricultural production in Ethiopia (CASCAPE). We thank prof. Ken E. Giller for his valuable suggestions and comments which improved the manuscript. Our thanks are extended to Sidama farmers for allowing us to harvest enset and khat plants and sharing their experiences of enset processing.

\section{References}

Abebe T., Wiersum K., Bongers F. (2010) Spatial and temporal variation in crop diversity in agroforestry home gardens of southern Ethiopia. Agroforestry Systems, 78, 309-322.

Amede T., Taboge E. (2005) Optimizing soil fertility gradients in the enset (Ensete ventricosum) systems of the Ethiopian highlands: Trade-offs and local innovations. In Advances in Integrated Soil Fertility Management in sub-Saharan Africa: Challenges and Opportunities, pp. 289-297. Eds A. Bationo, B. Waswa, J. Kihara, and J. Kimetu. Dordrecht, The Netherlands: Springer.

Brandt S.A., Spring A., Hiebsch C., McCabe G., Taboge E., Diro M., Wolde-Michael G., Ynitso G., Shigeta M., Tesfaye S. (1997) The 'tree against hunger': Enset-based agricultural systems in Ethiopia. Washington, DC: AAAS.

Dessie G. (2013) Favouring a demonised plant khat and Ethiopian smallholder enterprise. Current African Issues No. 51. Uppsala, Sweden: Nordic Africa Institute.

Feyisa T., Aune J. (2003) Khat expansion in the Ethiopian highlands. Effects on the farming system in Habro District. Mountain Research and Development, 23, 185-189.

Geresu B. (2015) Khat (Catha edulis F.) and cannabinoids: parallel and contrasting behavioral effects in preclinical and clinical studies. Pharmacology Biochemistry and Behavior, 138, 164-173.

Kandari L., Yadav H., Thakur A., Kandari T. (2014) Chat (Catha edulis): a socio-economic crop in Harar region, eastern Ethiopia. Springerplus, 3, 579. 
Kozak A., Kozak R. (2003) Does cross validation provide additional information in the evaluation of regression models? Canadian Journal of Forest Research, 33, 976-987.

Kumar B.M., Nair P.K.R. (2004) The enigma of tropical homegardens. Agroforestry Systems, 61, 135-152.

Megerssa B., Esayas A., Mohamed A. (2013) Socio-economic impact of khat in Mana district, Jimma zone, south western Ethiopia. Agricultural Science, Engineering and Technology Research, 1, 44-59.

Negash A., Niehof A. (2004) The significance of enset culture and biodiversity for rural household food and livelihood security in south western Ethiopia. Agriculture and Human Values, 21, 61-71.

Negash M., Starr M., Kanninen M. (2013) Allometric equations for biomass estimation of Enset (Ensete ventricosum) grown in indigenous agroforestry systems in the Rift Valley escarpment of southern-eastern Ethiopia. Agroforestry Systems, 87, 571-581.

Njiru N., Muluvi A., Owuor G., Jackson L. (2013) Effects of khat production on rural household's income in Gachoka Division Mbeere south district Kenya. Journal of Economics and Sustainable Development, 4, 54-63.

Nyombi K., Van Asten P.J.A., Leffelaar P.A., Corbeels M., Kaizzi C.K., Giller K.E. (2009) Allometric growth relationships of East Africa highland bananas (Musa AAA-EAHB) cv. Kisansa and Mbwazirume. Annals of Applied Biology, 155, 403-418.

RStudio (2015) RStudio: integrated development for R. Boston, MA: RStudio, Inc.
Seyoum K.A. (2015) Contribution of khat kellas and the impacts of its closure to Ethiopian economy (the case of Hararghe khat kella). Global Journal of Management and Business Research, 15, 21-29.

Snowdon P., Raison J., Keith H., Ritson P., Grierson P., Adams M., Montag K., Bi H., Burrows W., Eamus D. (2002) Protocol for sampling tree and stand biomass. Canberra, ACT, Australia: Australian, Canberra Greenhouse Office.

Taulya G. (2013) East African highland bananas (Musa spp. AAA-EA) 'worry' more about potassium deficiency than drought stress. Field Crops Research, 151, 45-55.

Tesfaye B. (2008a) On Sidama folk identification, naming and classification of cultivated enset (Enset ventricosum) varieties. Genetic Resources and Crop Evolution, 55, 1359-1370.

Tesfaye B. (2008b) The enset (Enset ventricosum) gardens of Sidama: Composition, structure and dynamics of a traditional poly-variety system. Genetic Resources and Crop Evolution, 55, 1347-1358.

Tsegaye A., Struik P. (2001) Enset (Ensete ventricosum (Welw.) Cheesman) kocho yield under different crop establishment methods as compared to yields of other carbohydrate-rich food crops. Netherlands Journal of Agricultural Science, 49, $81-94$.

Tsegaye A., Struik P. (2003) Growth, radiation use efficiency and yield potential of enset (Ensete ventricosum) at different sites in southern Ethiopia. Annals of Applied Biology, 142, $71-81$. 